\title{
Construcción de la marca en la era de los medios digitales
}

Vicente Ros Diego

Head of digital Havas Media

Las marcas están dejando de ser importantes para los consumidores, según informa el estudio de Havas Media ${ }^{1}$, que conecta las marcas con la calidad de vida y el bienestar de las personas y su impacto en el negocio.

Entre las principales conclusiones globales, revela que la desconexión entre las marcas y los ciudadanos persiste y que a la mayoría no les importaría que el $73 \%$ de las marcas dejaran de existir. Además, solo el 20\% de las marcas tienen un impacto positivo en la vida de las personas.

En este contexto de pérdida de confianza, construir marcas que sean para los consumidores pasa por crear una nueva relación entre marca y consumidor que contribuya a:

- Mejorar la vida de las personas, aportándoles beneficios reales y duraderos para los consumidores en cualquiera de los ámbitos que les atañen: Producto \& Servicio, Medio Ambiente, Lugar de Trabajo, Comunidad, Economía y Ética \& Gobierno.

- Gestionar el Social Capital, es decir, la calidad, profundidad, amplitud, y frecuencia de los diálogos, intercambios e interacciones referidos a una marca, que suceden dentro de una comunidad (entendiendo por profundidad el número de puntos de contacto con capacidad de influenciar que utilizamos, por amplitud el o alcance de la comunicación y por frecuencia el número de interacciones y el momento en el que se producen)

Estas dos mejoras constantes crean un círculo virtuoso de creación de valor que hace que las marcas sean para los consumidores, y que, se consiga un gran

1 Estudio de Havas Media. Disponible online en http://www.havasmedia.com/meaningful-brands 
valor de marca. Estas mejoras fomentan el desarrollo de Open Brands, marcas abiertas a conectar con el consumidor en cualquier lugar. Como caso destaca la conocida campaña de Tesco en Corea del Sur. Allí creó el primer supermercado realizado a partir de códigos QR insertados en las paredes del metro y sin la existencia de tiendas físicas. La acción aumentó en un 76\% el número de registros en la web e incrementó las ventas online en un $130 \%$.

Y es que en un entorno digital donde los medios incorporan nuevas tecnologías (Real Time Bidding, Tag Management, Universal Analytics, Database Intelligence...), y conectamos con el usuario a través de múltiples dispositivos y canales, la gestión integral de datos y el seguimiento de usuario desde la campaña hasta el, redes, o punto de venta, se convierten en clave para una mejor comprensión y optimización del y negocio de cada una de vuestras marcas.

El digital ha generado una cantidad ingente de datos, el famoso. Es indispensable su tratamiento y análisis para una mejor toma de decisiones; especialmente en el entorno económico actual. Podríamos decir que la era MAD MEN protagonizada por los publicitarios de los años 50 ha dado paso a la era de los MATH MEN, los hombres matemáticos.

El actual panorama de la publicidad ha cambiado brutalmente en los últimos 5 años. Ahora podríamos decir que . El ecosistema está creciendo y cambiando a toda velocidad, y cada día vemos como nuevas empresas lanzan novedosas herramientas. Este enfoque hacia los datos (), está sentando las bases hacia un nuevo modo de hacer las cosas. Si no se puede medir, nunca ocurrió.

Actualmente, los gigantes de Internet, y especialmente Google, son el modelo perfecto de compañías de datos masivos. El sistema de traducción automática de Google es un ejemplo de uso del ${ }^{2}$. En el 2006, Google lanzó su traductor con el objetivo de organizar la información del mundo y hacerla universalmente accesible y útil. Para lograrlo, volcó todo el contenido global de internet en su sistema, desde informes oficiales idénticos traducidos en varios idiomas hasta páginas web corporativas y personales que incluían traducciones de baja calidad. El traductor es capaz de establecer correlaciones con el fin de calcular, por ejemplo, las opciones de que una palabra siga a otra en inglés, o de interpretar cuándo la palabra significa ligero y cuándo se refiere a la luz.

Se abre paso a un análisis más profundo del consumidor, la marca y el mercado. Es necesario por tanto el desarrollo de planes de comunicación mediante contactos relevantes para el consumidor cuando, donde y como quiera.

El análisis de datos pasa por ser el pilar fundamental en cualquier plan de que quiera interactuar con el consumidor de manera eficaz. son contactos integrados, relevantes y que facilitan interacciones entre las marcas y los consumidores. El motor del es el Crecimiento Orgánico basado en Datos.

2 Blázquez, Susana: «El maná de los datos»., 29 de septiembre de 2013. Disponible en http://economia.elpais.com/ economia/2013/09/27/actualidad/1380283725_938376.html. 
El análisis de datos en tiempo real permitirá conversar con el usuario siendo más relevante para el mismo. En este ejemplo (Imagen 1) podemos ver un tuit promocionado para interactuar con el consumidor en el momento clave.

Imagen 1: captura de pantalla de un tuit promocionado

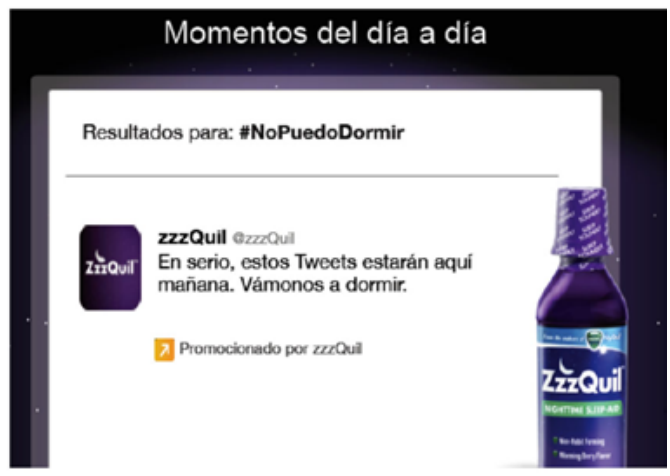

La medición integral en las agencias de comunicación es la base estratégica para la toma de decisiones. Medición que se irá desarrollando con metodologías como la modelización econométrica, la analítica web o el análisis de atribución.

Algunos modelos de atribución, permiten medir correlaciones existentes entre diferentes disciplinas digitales analizando por ejemplo, el impacto del en las conversiones procedentes de En este gráfico (Imagen 2) vemos como los usuarios impactados por la campaña de convirtieron hasta un $63 \%$ más que los no impactados. Además, la cesta de compra de usuarios impactados por la campaña de tenía un valor $21,9 \%$ más alto que los no expuestos.

Imagen 2: Usuarios impactados por la campaña de Real Time Bidding.

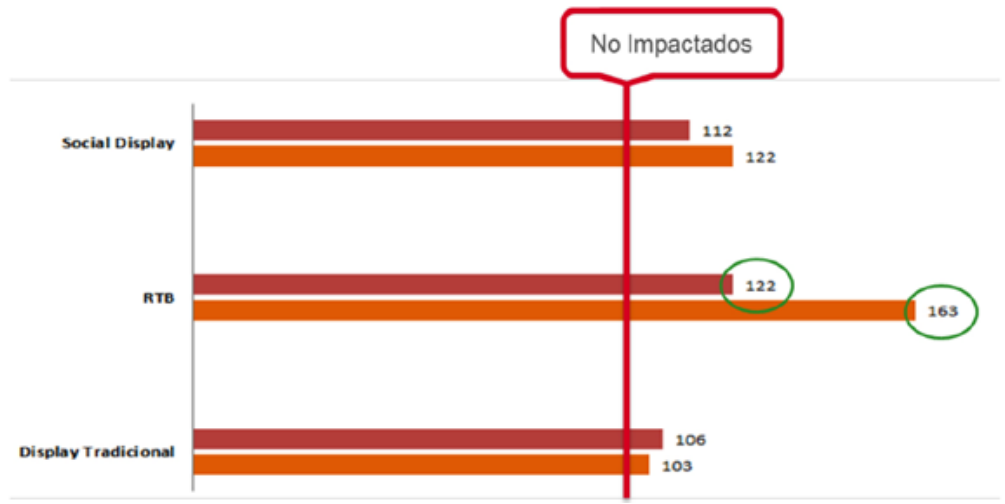


Toda marca que desee desarrollar debería considerar cinco aspectos clave en sus estrategias de comunicación:

1.Estar fundamentada en Data: Marcas como Shiseido cuentan con clubes de fidelización basados en el para incorporar los perfiles sociales a las fichas de sus socias, uniendo CRM tradicional con social. Así se sabe cuándo un usuario ha comprado en tienda y después comenta ese producto en Facebook.

2.Proporciona valor personal y social: Algunos proyectos corporativos pretenden crear un beneficio social. Bezoya ha desarrollado una campaña que combinaba un con interacción a través de Twitter con una acción en la calle donde una botella gigante se llenaba de agua gracias a la participación del público a través de Twitter. Se creó una botella que se llenaba con optimismo, un medidor en tiempo real del estado de ánimo de la gente, que se llenaba con mensajes positivos (\#QuedateConLoBueno) y se vacía con los negativos (\#LeydeMurphy). Finalmente, se convirtieron los mensajes positivos en pozos de agua potable en Filipinas.

3. Comparte historia de marca: Nivea Body Q10 creo la promesa «Conseguir una piel más firme en dos semanas». La fórmula era un tratamiento para estar en forma que constaba de tres elementos: dieta equilibrada, ejercicio físico y cuidado de la piel. Se trataba de una campaña de motivación personalizada que perseguía que las consumidoras concibieran el producto como parte de un tratamiento. En la página de la marca se podían conocer los Latin Motivus, y ver sus consejos: un entrenador, un chef y un especialista en cuidado de piel. A través de Facebook, los fans se inscribían a un plan personalizado de dos semanas, eligiendo el Latin Motivus preferido.

4.Estimula la conversación y la acción. permite interactuar con el consumidor cuando consume televisión. Para ello, algunas marcas pueden incorporar Shazam en sus spots para invitar a los usuarios a interactuar a través del móvil. La aseguradora AXA lanzaba una aplicación para cuyo objetivo era ayudar a los automovilistas a mejorar su conducción gracias a un análisis objetivo de su recorrido. Al ser activada por el conductor, la aplicación, llamada AXA Drive, analizaba las aceleraciones, los frenados y el modo de coger las curvas para obtener una evaluación precisa de los puntos fuertes y débiles de su conducción. A continuación, la le asignaba una puntuación, que quedaba registrada para que el usuario pueda consultar día a día su progresión. Un mapa detallado de los momentos clave del recorrido le ayudaba a comprender mejor su conducción y, además, se le envían consejos personalizados para optimizarla.

5. Conecta experiencias multiplataformas. La campaña Pro Evolution Soccer 2013 para Konami, diseñada por Havas se basaba en la idea de hacer «entrar» al juego a un fanático del juego. Una experiencia única alrededor del mundo del fútbol por el que se convirtió a un fan en uno de los protagonistas del videojuego. Un evento seleccionó al «jugador total», aquel que más habi- 
lidades demostró tanto con el balón como con el mando de la consola. El ganador, Eduardo Morillo, visitó el cuartel general de Konami en Japón donde los propios desarrolladores del juego digitalizaron su imagen y movimientos usando las más avanzadas técnicas de postproducción digital para crear un avatar super-realista del jugador.

Las marcas que realmente sean capaces de desarrollar plataformas multimedia que conecten con el consumidor en cualquier momento y lo hagan protagonista serán finalmente más en el entorno digital actual.

\section{Referencias}

Blázquez, Susana: «El maná de los datos»., 29 de septiembre de 2013. Disponible en http://economia.elpais.com/economia/2013/09/27/actualidad/1380283725_938376.html. (4/05/2014).

\section{Referencia de este artículo}

Ros, Vicente (2014). En: adComunica. Revista Científica de Estrategias, Tendencias e Innovación en Comunicación, $\mathrm{n}^{0} 7$. Castellón: Asociación para el Desarrollo de la Comunicación adComunica, Universidad Complutense de Madrid y Universitat Jaume I, 205-209. DOI: http://dx.doi.org/10.6035/2174-0992.2014.7.14. 